\title{
Assessing the Validity of Zero Conjectural Variation Hypotheses in Competition in Nigerian Sugar Industry
}

\author{
C. Chris Ofonyelu ${ }^{1, *}$ \\ ${ }^{1}$ Department of Economics, Adekunle Ajasin University, Akungba Akoko, Ondo State, \\ Nigeria \\ *Correspondence: Department of Economics, Adekunle Ajasin University, Akungba Akoko, \\ Ondo State, Nigeria. Tel: 234-803-626-3154 E-mail: chijiokechris@yahoo.com
}

Received: October 3, 2014 Accepted: November 14, 2014 Published: December 22, 2014 doi:10.5296/rae.v6i4.6820 URL: http://dx.doi.org/10.5296/rae.v6i4.6820

\begin{abstract}
The crux of Cournot and Bertrand theory of industrial relationship is based on zero conjectural variation in output and Prices. The two theories assume that firms form constant expectations about their rival's reaction during output and price competition. This study examined the validity of zero conjectural variation hypotheses within the context of the competition in Nigerian sugar industry. Using a two-stage least square analogy and data of wholesale sugar prices between January 2007 and June 2014, the study examined the interrelationships in the firms' price and output competition. Evidence from the study showed positive conjectural variation among the sugar firms, suggesting that output and price of rival firms varied with competition. The strong interdependency among the sugar firms suggests a continued long run competition and stable price in the industry.
\end{abstract}

Keywords: Cournot theory, Bertrand theory, Conjectural variation, Collusion

JEL classification codes: L11, L16, M31 


\section{Introduction}

The traditional theory of oligopolistic competition assumes that firms form expectations about the reactions (or variations) of their rivals. This technically is referred to as conjectural variations. Specifically, Cournot (1838) and Bertrand (1883) theories had their theoretical foundation on zero conjectural variations in output and price respectively. Based on Cournot model, firms choose the competitive output level and let the demand curve determine price while firms in the Bertrand model choose price as the competitive variable, leaving the demand curve to determine output. Implicit in the models is that both price and output variables cannot be determined simultaneously but that each mirrors the pattern of competition faced by the individual firm. The two models rest on very specific assumptions. There are at least two non cooperating firms producing a homogeneous product. Each of the firms competes all together for quantity (or prices) as consumers want to buy everything from the firm with the lower price. In the case of the Nigerian food and beverage industry, competitions in the sugar industry satisfy these assumptions except for the presence of brand differentiation and possession of market power by individual firms. For the most part, sugar is traded as a homogenous product and serves as perfect substitutes but branding by individual firms serve as a source of differentiation. The competition in the sugar industry occurs among a very few number of firms. In particular, Dangote Sugar Refinery (DSR), BUA Sugar Refinery (BSR) and Golden Penny Sugar Refinery (GPSR) are the three major players in the industry and account for over $95.0 \%$ of the total industry output. Among the three, DSR controls over $60 \%$ of the industry output, leaving BSR and GPSR with market shares of $31 \%$ and $6 \%$ respectively. Inherent in the competitive structure is that the firms are geographically concentrated in Lagos, and supply the other parts of the country there from. The single locational concentration contributes to increasing the interdependency and rivalry among the firms.

The aim of this study is to determine whether within the competitive relationship of partial product differentiation as the case in Nigerian sugar industry, there exists constant variation in the rival firms' output in the industry. The existence of zero conjectural variation suggest that rival firms' output and price functions are sticky and invariant in competition. The rest of this paper is sectioned as follows. Section II discussed some stylized facts on competitions in Nigerian sugar industry. Section III contains the methodology, while sections IV and V present the results and conclusion respectively.

\section{Stylized Facts on Competitions in Nigerian Industry}

The setting up of the National Sugar Development Council (NSDC) in 1993 was a major effort at raising the domestic production capacity of the industry. As at the time, the domestic production capacity lagged behind demand by over 650,000 tons per annum. The NSDC was aimed then at increasing the capacity of the existing country's sugar companies (Note 1) through privatisation. The privatization of the sugar firms led to a dilution in the ownership structure of the sugar firms. In effect, Savannah and Nigeria Sugar Companies became taken over by Dangote Group and Josepdam \& Sons in 2002 and 2006 respectively. In 2008, the 
BUA Group acquired Lafiaji Sugar Company. The latest of the acquisitions was the takeover of Sunti Sugar Company by Flour Mills Nigeria (FMN) in 2009. The privatized companies did not begin serious production activity until late 2009. In effect, the refining capacity in the industry grew rapidly in the years following. For instance in the years 2012 and 2013, the refining capacity to grew by $60 \%$ and $75 \%$ respectively. Something spectacular in the privatization was that competitions increased among the firms, arising mainly from enlarged capacity utilization and change in the marketing strategy of the emerging firms as a result of change in ownership.

Two factors underline competition in the sugar industry. First, the industry is marked by the presence of very few geographically concentrated firms. Industrial conduct and performance are known to be determined by firms' size and concentration (Corley, 1990). Second, with the fewness arises a strong rivalry between the firms in terms of price and output competition. The oligopolistic competition is between three firms, DSR, BSR and GPSR. The three firms are located in Lagos and produce brands known by the names Dangote, Bua and Golden Penny sugar.

Table 1. Refining capacities and market shares of the sugar firms

\begin{tabular}{cccc}
\hline Sugar Firm/ Refinery & $\begin{array}{c}\text { Potential capacity per annum } \\
\text { (in million metric tonnes) }\end{array}$ & $\begin{array}{c}\text { Market share as \% of } \\
\text { industry }\end{array}$ & $\begin{array}{c}\text { Proportion of } \\
\text { installed capacity used }\end{array}$ \\
\hline Dangote sugar & 1.44 & 60 & 90 \\
Bua sugar & 0.72 & 31 & 60 \\
Golden penny sugar & 0.14 & 6 & 25 \\
Total & 2.30 & 100 & --- \\
\hline
\end{tabular}

Source: computed from sales and production profile of the firms

In terms of capacity, DSR is the largest in terms of installed capacity (of 1.44 million metric tons per annum), and its capacity is equivalent to $63 \%$ of the total industry refining capacity. Bua and Golden penny sugar firms have potential capacities of 720,000 and 140,000 metric tonnes per annum respectively. In terms of market share, DSR controls over $60 \%$ share of the sugar market with about $10 \%$ of its current refining capacity being idle. This compares to BSR and GPSR which are both operating at $45 \%$ and $12 \%$ of their installed refining capacity per annum (see table 1). In term of period of entry into the industry, DSR and BSR had had their brands in the market over the years until GPSR joined the market in late 2012. Flour mills of Nigeria (FMN), the parent company of GPSR, upon the entrance invested heavily on the establishment of the sugar refinery, and attached additional incentive for the flour distributors (and customers) that purchased its own sugar. The firm used the later part of 2012 to market and introduce the products to the market (Note 2), while actual competition for market share and penetration started in early 2013. The entrance of the Golden Penny sugar into the market precipitated a major crash in the price of sugar in the Nigerian market. Being the market leader, Dangote sugar slashed the wholesale price of 50-kg bag of sugar from the average of N9800 in 2012 to N6500 in 2013 (see table 2). For instance in 2012, during the Ramadan season (Note 3), the wholesale price of sugar peaked at N11200. This contrasts with the peak price of N7500 recorded in 2013 at the commencement of the fasting season. Owing to the strength of FMN, 
which controls the dominant share of the flour market, the entry of golden penny sugar was strictly resisted by the other two rivals. The GPSR would have naturally collapsed had it not had the support of its parent firm with the kind of stiff barrier it faced at the entrance. The entry raised the tempo of competition in the industry from what used to be mild and regionally structured, to a total battle for market share and profitability. Golden penny sugar banked on the size advantage the parent company has in flour production to compete with the other established sugar firms, but the stiff contest posed by the existing firms was really far beyond what the firm had expected. With barely two years into sugar production, the firm had not quite been able to sustain large-scale continuous production because of the small market share it was able to capture.

Table 2. Wholesale invoice price of 50-kg bags of sugar

\begin{tabular}{rrcc}
\hline Date/ Brand & Dangote & Golden Penny & Bua \\
\hline $13 / 12 / 2007$ & 2400 & $\mathrm{Na}$ & 2300 \\
$31 / 12 / 2008$ & 3200 & na & 3100 \\
$31 / 12 / 2009$ & 4800 & na & 4750 \\
$31 / 12 / 2010$ & 7500 & na & 7400 \\
$31 / 12 / 2011$ & 7200 & na & 7150 \\
$31 / 12 / 2012$ & 9800 & na & 9700 \\
$31 / 12 / 2013$ & 7100 & 7150 & 7150 \\
$31 / 07 / 2014$ & 6800 & 6750 & 6750 \\
\hline
\end{tabular}

Source: Computed from Sales Invoice of the Sugar refineries excluding transport fare rates.

Note: (i) For those years that price changed, the average for the years was reported

(ii) Golden Penny sugar commenced sales in 2013.

The entrant of GPSR raised the production capacity in sugar refining from an initial estimated national need of 1.45 million tons per year to a total capacity to 2.3 million tons per annum as at 2013. The excess capacity created implied that the firms have to operate below their full capacities as they compete. The excess capacity gives room for firms to vary output and price as well as give room for the use of capacity as avenue for competition (Eaton, Jonathan and Grossman, 1984). Evidence of conjectural variation derives from the nature of competition and competitive structure of the industry concerned (Sheth, 1986). The capacity utilization of a firm reflects the competitive structure. In view of this, the cross elasticity of the firms' output can be used to approximate conjectural variation. Prior to the entrant of GPSR, DSR operate at near full capacity utilizations such that when there was break down in its production in 2012, the excess demand significantly generated price shocks through the market. The entrant of GPSR in the last two years contributed to the sharing the market and easing the relative strength of each individual firm in the industry. In order to increase the share of the market, DSR introduced a wide range of products such as the Vitamin A fortified sugar packages in one kilogram, 500 grams and 250 gram packs. The fortified white sugar was launched into the market to achieve the set target of higher sales volume, earnings and ultimately profitability. This had was matched GPSR on its entrance to the industry. Firms are known to increase their investment in capacity during competition (Davidson and Deneckere, 1990). This had played out in the industry as competition for corporate consumers intensify in 
the industry.

Table 3. Firm competition among some selected industrial users in Nigeria

\begin{tabular}{ll}
\hline Firms & Sugar supplier \\
\hline Nigerian Guiness & Dangote \\
Nigerian Brewery & Dangote \\
DANSEA Juice & Dangote \\
Pumman & Dangote \\
Coca-cola Bottling Co & Dangote \\
7-Up Bottling Co. & Dangote \\
Lacasera Drinks & Dangote \\
Yale Biscuit & Bua \\
ShopRite & Bua \\
\hline
\end{tabular}

\section{Source: Author's compilation}

Based on table 3, industrial consumers tend to favour established firms as their suppliers. Mainly, the capability of firms to offer lower price and ensure steadiness of supply is a major consideration in this regard. The DSR enjoyed the highest advantage in this regard because of its established size and capability. GPSR had lagged behind in sustaining industry supply, mainly because of the late entry and stiff competition.

\section{Methodology}

The Cournot (quantity) and Bertrand (price) setting analogy is premixed on a number of identifiable assumptions. The accuracy of each of the predictions depends on the closeness of either model to the industry situation. The general rule of the thumb is that when capacity and output are variable, the Bertrand model is preferred. However, when output and capacity are difficult to adjust, the Cournot is generally employed (Dixon, 1986). The case of the sugar industry is such that adjustment of capacity utilization is relatively sticky in the short-run. In view of this, the Cournot equivalence is commonly used for analysis of duopolistic relationships (Ma, 2005). In practise, the Cournot model can be recasted as a two stage model when discussed with the context of conjectural variation. Following the foregoing presupposition, a firm in the first stage chooses the productive capacity to built, and compete for output (or price) in the second stage (see Ofonyelu, 2014). We assume a non collusive competition among two firms, such that there is an asymmetry in terms of the market share holding ad capacity utilization of individual firms, the resulting inverse linear demand function given as:

$$
P(Q)=a-b\left(q_{i}+Q_{g}\right)
$$

Where and represent the price and quantity demanded respectively. The price arises from the production capacities of the firms, while the demands arise from the utility-maximizing behaviour of the consumers. In equilibrium, the market quantity demanded equals the sum of the outputs of all the firms participating in the market, and thus reflects the aggregate demand 
of all consumers of refined sugars. Given $n$ firms producing quantity of refined sugar in a market and a dominant firm producing, we can examine the interrelationship between the two firms using conjectural variation analogy. The dominant firm is such that it has the potential capacity to satisfy the whole industry. We represent the output of the dominant firm, hereby referred to the Dangote sugar firm. Given that the industry output is $Q=\sum_{\mathrm{i}=1}^{\mathrm{n}} \mathrm{Q}_{\mathrm{j}}+Q_{d}$, and that $Q_{J}=\sum_{\mathrm{j} \neq 1}^{\mathrm{n}} \mathrm{Q}_{\mathrm{j}}=\mathrm{Q}-Q_{d}$ represents the combined output produced by the other firms, Bua and Golden penny sugar firms. In the succeeding section, we can simulate the quantity price interactions between the firms. The firms are assumed to have a uniform cost function (Note 4$), C_{i}\left(Q_{i}\right)$, which is a common knowledge to all. If we assume that the cost structure is the channel through which firms make their price and output decision, firms' profits varies in response to their capacity utilization and output levels. Firms operating at fuller capacity will maximize profit than those with greater idle capacity. The Dangote firm has the dominant market share as well as the leading capacity utilization. If we designate the cost structure according to individual firms, the maximization objective can be written as:

$$
\begin{aligned}
\operatorname{Max} \Pi=\mathrm{P}(\mathrm{Q}) & \mathrm{Q}_{\mathrm{d}}-\mathrm{C}_{\mathrm{i}}(\mathrm{Q}) \\
& =\left[a-b\left(q_{i}+Q_{d}\right)\right] Q_{d}-C_{d}\left(Q_{d}\right) \\
& =\left[a-b\left(q_{i}+Q_{d}\right)\right] q_{i}-C_{i}\left(q_{i}\right)
\end{aligned}
$$

Equations (2) and (3) describe the profit functions of the two firms. The equilibrium condition of an oligopoly market requires that the marginal revenue equal the marginal costs of each of the firms $\left(\mathrm{MR}_{\mathrm{i}}=\mathrm{MC}_{\mathrm{i}}\right)$. The maximization problem resolves to

$$
=\frac{\mathrm{d}\left(\mathrm{a}-\mathrm{b}\left(q_{i}+Q_{d}\right)\right)}{d Q_{d}} Q_{d}+a-b\left(q_{i}+Q_{d}\right)-\frac{\mathrm{d} C_{d}\left(Q_{d}\right)}{d Q_{d}}=0
$$

Without loss of generality, the firm's problem can be given as:

$$
=\frac{\mathrm{d}\left(\mathrm{a}-\mathrm{b}\left(q_{i}+Q_{d}\right)\right)}{d q_{i}} q_{i}+a-b\left(q_{i}+Q_{d}\right)-\frac{\mathrm{d} C_{i}\left(q_{i}\right)}{d q_{i}}=0
$$

We can therefore rewrite (4) and (5) further as

$$
\begin{gathered}
Q_{d}=\frac{\mathrm{a}-\mathrm{b} q_{i}-\mathrm{d} C_{g}\left(Q_{d}\right)}{d q_{d}} / 2 \\
q_{i}=\frac{\mathrm{a}-b Q_{d}-\mathrm{d} C_{i}\left(q_{i}\right)}{d q_{i}} / 2
\end{gathered}
$$

Equations (6) and (7) are the reaction functions of the firms. For any value of, firm 1 responds best with any value of $Q_{d}$ that satisfies the equations. The profit level depends on the output level, and this is endogenous to the capacity utilization level of each firm. By substituting for $q_{i}$ in the Dangote firm's best response:

$$
Q_{d *}=\left[a+\frac{\mathrm{d} C_{i}\left(q_{i}\right)}{d q_{i}}-2\left(\frac{\mathrm{d} C_{d}\left(Q_{d}\right)}{d Q_{d}}\right)\right] / 3
$$




$$
q_{i *}=\left[a+\frac{\mathrm{d} C_{g}\left(Q_{d}\right)}{d Q_{d}}-2\left(\frac{\mathrm{d} C_{i}\left(q_{i}\right)}{d q_{i}}\right)\right] / 3
$$

Since we were interested in the nature of relationship between the firms, it would be adequate to assume the other smaller firms in the industry to have same conjectural response with the dominant one, such that for all the small firms (hereby representing Bua and Golden Sugar). Given that capacity utilization is determined in the first stage, the conjectural variation model can be defined following Ma (2005) as

$$
\phi=\frac{d Q_{d}}{d q_{i}}
$$

The Cournot approximations of oligopolistic competition propose that each firm will attempt to maximize its profit subject to zero conjectural variation in rival's output. This in effect means that $d q_{i} \neq 0 \quad$ Otherwise, $\phi_{\mathrm{i}}=\infty$. Equation (10) $=0$ suggests that $d Q_{g}=0$ such that (8) and (9) reduces to (11) and (12) respectively:

$$
\begin{gathered}
Q_{d * *}=\left[a+\frac{\mathrm{d} C_{i}\left(q_{i}\right)}{d q_{i}}\right] / 3 \\
q_{i} * *=\left[a-2\left(\frac{\mathrm{d} C_{i}\left(q_{i}\right)}{d q_{i}}\right)\right] / 3
\end{gathered}
$$

Equation 11 shows that $Q_{d}>q_{i}$. Based on the assumption that $q_{i}=q$, increase in the sale of dangote sugar brand implies reduction in the market share available to the $q_{i}=q$ firms. For the firms, only the competitive survives the market, giving the market leader firm the characteristic power as a monopolist (Ekanem and Iyoha, 2000). The extent to which each of the firms experiences changes in their outputs is related to their useable idle capacities. In effect, more dominant firms will harbour smaller capacity utilization while acquisition of newer capacity would imply increasing strategy for new market. A firm's idle capacity will reflect the potential supply which could be released to the market in the short run without recourse to building additional capacity. Implicit in the size of this capacity is the potential output that could be supplied to the market in the short run. The foregoing analogy implies that changes in capacity and/or output are proxies for conjectural responses. Based on this assumption, equation (10) can be redefined as:

$$
\phi=\frac{d Q_{d}}{d q_{i}} * \frac{M_{i}}{M_{d}}
$$

where $M_{i}$ and $M_{d}$ represents the market share of other firms and Dangote respectively. In a situation where we make specific reference to a particular firm, appropriate subscript will be attached to denote the firm in question. In table 5, the calculations of the conjectural variation for Bua and Golden penny brands were indexed on Dangote sugar brand. In an oligopoly industry where competing firms have varied market share, the likelihood of the variation manifesting in pricing behaviour (even with uniformity in the cost of production) are more probable. Thus, despite market concentration, firms would not want to collude as indivival profit dominates whatever is the collusive gain on the side of the firms (Raible, 2013). 


\section{Results and Findings}

The activity of the sugar industry is notable because sugar serves as a major input for a number of firms within the food and beverage subsector. For instance, refined sugar provides critical raw materials for the food, beverage and pharmaceutical industries. Specifically, the food and beverage subsector represent the largest consumer in the supply chain of the sugar industry. Specifically, the sector accounts for about $41.0 \%$ of the total industrial sugar consumption in Nigeria in 2006 (Gourichon, 2013). By being a major supplier to industrial consumers, a firm is sure to build huge production capacity. The cross correlation coefficient computed showed a strictly strong correlation coefficient. The implication of this is that there exist a strong relationship and interdependency among the competing firms.

Table 4. Price correlation coefficient among the three dominant sugar firms in Nigeria

\begin{tabular}{ccc}
\hline Sugar Firms & Dangote vs Bua & Dangote/Bua vs Golden \\
\hline $\mathrm{R}(2007-10)$ & 0.999 & --- \\
$\mathrm{R}(2010-14)$ & 0.991 & --- \\
$\mathrm{R}(2007-14)$ & 0.994 & 1 \\
\hline
\end{tabular}

Source: computed from table 2

Table 4 shows a strong, but marginally declining inter-rivalry among the categories of the sugar firms. The nearer $\mathrm{R}$ is to $1(\mathrm{R} \rightarrow 1)$, the stiffer the competition between the rival firms in question. In term of competitiveness, Golden penny sugar is worst competitive as the correlation coefficient between it and the other competitors was unitary; suggesting that its marketing strategies were strictly being countered by the other firms (Dangote and Sugar). In effect, increasing market capture by the firm is made nearly impossible. The marginal reduction in the intensity of the rivalriness over the years can be attributed to rise in the demand for sugar in recent years (2007-2010 compared to 2010-2014). The new demands were driven mainly by new producers of soft and carbonated drinks as well as other sugary products which are increasingly introduced into the household (Note 5) consumptions bundle. This derived have been aided by a growing young population. A positive coefficient of conjectural variation suggests a direct relationship between the firms concerned.

Table 5. Coefficient of conjectural variation

\begin{tabular}{cc}
\hline Sugar Brands & Dangote $(\phi)$ \\
\hline Bua & 1.048 \\
Golden Penny & 1.053 \\
\hline
\end{tabular}

Source: Computed

The positive non-zero coefficient of $\phi$ shows that output competition among the firms is varying(Note 6). The positive coefficient suggests a strong elasticity for the demand of sugar from the eyes of the consumers. The strong interdependency suggests increased competition in the industry. In view of this, firms capturing large market share becomes key to long-term profit maximization. Long-run competition has the potential of stabilizing price. For a 
commodity as sugar, the impact of the low price may be substantial in view of the dominance of food prices in the composite bundle for the computation of the consumer price index (CPI). This is thought good as rise in the price of food and beverage products constitute a major inflation trigger for the economy. Compared to mixed conjectural variation obtained for the flour firms, competitions in the sugar industry is strictly positive (see Ofonyelu, 2014). Two factors may have accounted for this difference. First, there are more firms participating in the flour industry, with the top three controlling over $80 \%$ of the industry market share. The skewed capacity of the participating firms implied that their conjectural variation cannot be uniform. Second, the market and productive capacity in flour industry is larger; permitting firms to exist at regional levels. Unlike in the flour industry, sugar firms are concentrated around the same location and each produce for the national market. The existence of positive conjectural variation in the industry suggests that firms are closely interdependent. The existence of stiff competition is suggested as a reason why collusion short-run collusion may not be likely as in the case of the flour industry.

\section{Conclusion}

The paper employed a two-stage analogy to assess the validity of zero conjectural variation hypothesis as proposed by Cournot (1838) and Bertrand (1883) using Nigerian sugar industry as a case study. The existence of zero conjectural variation suggest that rival firms' output and price functions remain sticky and invariant during competitions. The result from the study showed that the competing firms exhibited positive conjectural variations in their output competitions. The finding was suggestive that the firms' outputs were actually varying in competition and interdependent. The positive values of the conjectural variation coefficient among the sugar firms suggest a strong elasticity of demand among the firms. In view of this, when a firm alters its price, such action will most likely be retaliated. Otherwise, it will sweep over customers of the other firms. The strong interdependency among the sugar firms is indicative of continuous long run competition and stable price.

\section{References}

Bertrand, J. (1883). Book review of theorie mathematique de la richesse sociale and of recherches sur les principles mathematiques de la theorie des richesses. Journal de Savants, 67, 499-508.

Cournot, A. (1838). Researches into the Mathematical Principles of the Theory of Wealth. N. Bacon. Eds. Macmillan. Reprinted 1897.

Corley, T. B. A. (1990). Emergence of the theory of industrial organization, 1890-1990. Business and Economic History, 19, 83-92.

Davidson, C., \& Deneckere, R. (1990). Excess Capacity and Collusion. International Economic Review, 31, 521-541. http://dx.doi.org/10.2307/2527159 
Dixon, H. D. (1986). Strategic Investment with Consistent Conjectures. Oxford Economic Papers, 38, 111-128.

Ekanem O. T., \& Iyoha, M. A. (2000). Microeconomic Theory. (2nd ed.). Mareh Publishers, Benin City, Nigeria.

Gourichon, H. (2013). Analysis of incentives and disincentives for sugar in Nigeria. Technical Notes Series, MAFAP, FAO, Rome.

Eaton, J., \& Grossman, G. (1984). Strategic Capacity Investment and Product Market Competition. Discussion paper 80, Woodrow Wilson School.

Ofonyelu, C. C. (2014). Strategic capacity utilization and competition: An Analysis of Competitions in Nigerian Flour Industry. Issues in Business Management and Economics, 2(10), 186-192. http://dx.doi.org/10.15739/IBME.2014.005

Ma, T. (2005). Strategic Investment and Excess Capacity: A study of the Taiwanese Flour Industry. Journal of Applied Economics, 8(1), 153-170.

Raible, M. (2013). Industrial Organization theory and its contribution to decision-making in purchasing. University of Twente, Faculty of Management and Governance.

Sheth, J. N. (1986). New Determinants of Competitive Structures in Industrial Markets. University of Southern California. Retrieved on 10.06.2014 from www.researchgate.net/...New_Determinants_of_Competitive_Structures

\section{Notes}

Note 1. The sugar companies include the Savannah Sugar Company Limited at Numan, Adamawa State; Nigeria Sugar Company at Bacita, Kwara State; Lafiaji Sugar Company in Kwara State; and Sunti Sugar Company in Niger State.

Note 2. The introduction of the product was a major agenda at the 2012 customers' forum of the flour mill.

Note 3. The demand for sugar during the fasting season of Ramadan is known to increase, and so also the price. As has become a tradition in the industry, the highest demand and prices are usually recorded during the season.

Note 4. The cost function is assumed to tend to uniformity as all the firms import sugar at the same market and refine same using similar technology.

Note 5. Household consumption and demand for sugar accounts for about 50\% of the total industrial usage.

Note 6. Similar outcome is expected in price competition. 


\section{Copyright Disclaimer}

Copyright for this article is retained by the author(s), with first publication rights granted to the journal.

This is an open-access article distributed under the terms and conditions of the Creative Commons Attribution license (http://creativecommons.org/licenses/by/3.0/). 